\title{
Medveállatka (Tardigrada) fajok előfordulása Somogy megyében
}

\author{
VARGHA BÉLA - IHAROS GYULA
}

\begin{abstract}
VARGHa B. and Iharos Gy.: Occurence of the water - bear (Tardigrada) species in Somogy county. Abstract: Authors summarize the reports of the occurence of tardigrade species in Somogy county. At present 55 species, from 2 classes, 3 orders, 5 families and 15 genera known from the area representing $45 \%$ of the Hungarian tardigrade fauna.
\end{abstract}

\section{Bevezetés}

Somogy megye területérôl medveállatkákat elôször IHAROs írt le 1937-ben. Zákány térségéből származó mohamintában 2 faj jelenlétét állapította meg.

Ezt követoóen 1960 -ban ugyancsak IHAROS tudósít 6 lelőhelyröl (Balatonmáriafürdô, Buzsák, Hollád, Kéthely, Somogysámson, Táska ) gyújtött mohamintákban talált 12 újabb fajól.

A Barcsi borókás területéről (Barcs, Darány és Szulok környéke) gyújtött talaj, avar, fakorhadék, moha, tốzegmoha, zuzmó minták vizsgálata 28 Tardigrada faj előfordulását jelezte (IHAROS 1981, 1985), amely újabb 16 fajjal gyarapította a Somogy megyében előforduló fajok számát.

A Zselic Somogy megyei részéból (Bárdudvarnok, Bőszénfa, Cserénfa, Gálosfa, Kadarkút, Kercseliget, Mosdós, Nagypuszta, Szenna, Szentbalázs, Zselickisfalud, Zselickislak) származó talaj, avar, fakorhadék, moha és zuzmó mintákból IHAROS és VARGHA (1995) 31 medveállatka fajt mutatott ki, amelyek közül 12 faj eddig ismeretlen volt Somogy megyéből.

VARGHA (1996) hazánk területéről eddig még nem ismert fajt talált először siófoki mohamintában.

A Duna - Dráva Nemzeti Park Somogy megyei területén (Barcs, Bélavár, Darány, Szentborbás, Tótújfalu, Vízvár) gyújtött talaj, avar, moha és zuzmó mintákból VARGHA (1998) 32 Tardigrada faj jelenlétét állapította meg, amelyek közül 11 faj új a Somogy megyei faunára, kettő pedig új a hazai faunára is.

További, Somogy megye területérôl (Balatonföldvár, Balatonlelle, Balatonmáriafürdő, Balatonszemes, Igal, Kapoly, Nemesvid, Siófok, Tab, Zala) származó moha és zuzmó mintákból VARGHA (jelen tanulmány) 17 fajt mutatott ki, amelyek közül azonban mindössze egy faj nem volt eddig ismert Somogy megyéból (1. táblázat).

Az egyes gyưjtốhelyeken előforduló medveállatka fajokat a 2. táblázatban, míg az egyes Tardigrada fajok előfordulását a 3. táblázatban mutatjuk be.

A Somogy megyében elốforduló medveállatkák rendszertani egységenkénti számát a 4. táblázat, fajlistáját pedig az 5 . táblázat tartalmazza.

Jelenleg a Somogy megye területéról leírt medveállatka fajok száma 55, amely a hazai Tardigrada fauna ( 123 faj ) $45 \%$-a, és a Dunántúlról ismert fajok ( 114 ) $48 \%$-a. 
1. táblázat: Tardigrada fajok Somogy megyei előfordulásának közleményei

\begin{tabular}{|c|c|c|c|c|c|c|c|c|}
\hline \multirow[b]{2}{*}{ Tardigzada fajok } & \multicolumn{8}{|c|}{ Kïzleménvek } \\
\hline & $\begin{array}{c}\text { IHAROS } \\
1937\end{array}$ & $\begin{array}{c}\text { IHAROS } \\
1960\end{array}$ & $\begin{array}{c}\text { IHAROS } \\
1981\end{array}$ & $\begin{array}{c}\text { IHAROS } \\
1985\end{array}$ & $\begin{array}{c}\text { IHAROS- } \\
\text { VARCHA } \\
1995\end{array}$ & $\begin{array}{c}\text { VARGHA } \\
1996\end{array}$ & $\begin{array}{c}\text { VARGHA } \\
1998\end{array}$ & $\begin{array}{l}\text { VARGHA } \\
\text { jelen tan. }\end{array}$ \\
\hline Echiniscus hisctosus & & & & & $x$ & & & \\
\hline Edhiniscts. cumeretousis & & & & & $x$ & & & \\
\hline Echiniscus vormulatus & & & $\mathrm{x}$ & & & & & \\
\hline Echiniscus mediantus & & & & & $x$ & & & \\
\hline Echinisaus tfuddrispinosus & $x$ & $x$ & & & & & & \\
\hline Erhiniscas testude & & & $x$ & $x$ & $x$ & & & $x$ \\
\hline Echiniscass trisctusstes & & & & & $x$ & & & \\
\hline Pseculuchiniscuss suilless & & $\mathrm{x}$ & $x$ & & 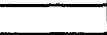 & & & \\
\hline 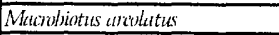 & & & & & $x$ & & & \\
\hline Mecrolhotus fummersumthi & & & & $x$ & $x$ & & $\mathrm{x}$ & \\
\hline Mecouliotis Intfoltendi & & $\mathrm{x}$ & $x$ & $x$ & $x$ & & $x$ & $\mathrm{x}$ \\
\hline Mecrobliotus mucnealix & & & & & & & $\mathrm{x}$ & \\
\hline Macribiotus pullarii & & & & & & & $x$ & \\
\hline Mecroliotus richtewis & & $x$ & $x$ & $x$ & $x$ & & $x$ & $\mathrm{x}$ \\
\hline Mucrobiotus sublinterntedius & & & & & $x$ & & 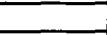 & \\
\hline Xerrobiotus pseruloluffeclendi & & & & & & & $x$ & \\
\hline Minibiotus furrestus & & & & & & & $x$ & $\mathrm{x}$ \\
\hline Minilhotus intemuelius & $x$ & & $x$ & $\mathrm{x}$ & $x$ & & $x$ & $x$ \\
\hline Haxupodibius lindac & & & & & & & $x$ & \\
\hline Hyysilnizs comperyers & & $\mathrm{x}$ & $x$ & $\mathrm{x}$ & $x$ & & $x$ & $x$ \\
\hline Hyysibius dajomelini & & $x$ & & $x$ & $x$ & & $x$ & \\
\hline Hypsilhius micongs & & $x$ & $x$ & $x$ & - & & 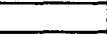 & \\
\hline Hywsilhius pullidus & & $x$ & $\mathrm{x}$ & $x$ & $x$ & & $x$ & $\mathrm{x}$ \\
\hline Isoluypsibius beromuriensis & & & $\bar{x}$ & $x$ & & & $x$ & \\
\hline Isolivpsilhius Imovispinasus & & & & & & & $x$ & \\
\hline Isoluppsilins destestydii & & & & 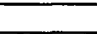 & & & $x$ & \\
\hline 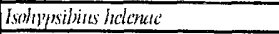 & & & & $x$ & 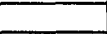 & & & \\
\hline Isofinysilhius leithuicus & & & . & & $x$ & & & \\
\hline 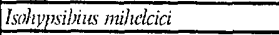 & & & $\mathrm{x}$ & 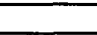 & $x$ & & - & \\
\hline Isolyplsibizizs nodosus & & $\mathrm{x}$ & & $x$ & $x$ & & & \\
\hline Isolypsilinus peippi & & & & & $x$ & & 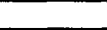 & $x$ \\
\hline Isohpusithits pnosostonus & & & & & $x$ & & $x$ & $\mathrm{x}$ \\
\hline Isolyyssilhitus nussissutllci & & & & & & & $x$ & \\
\hline Isolyypsibius schunulinni & & $x$ & $x$ & $x$ & $x$ & & $\mathrm{x}$ & $\mathrm{x}$ \\
\hline Isollopsihinus sil ricaller & & & & & $\mathrm{x}$ & & $x$ & \\
\hline 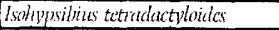 & & & & $x$ & & & & $\mathrm{x}$ \\
\hline Isolhypsibinus undulutus & & $\mathrm{x}$ & & & & & 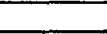 & \\
\hline Encmubliotus alicattai & & & & & & $\mathrm{x}$ & $x$ & $x$ \\
\hline Deryphonifius macrodon & & & & & $x$ & & $x$ & \\
\hline Psemtlobnotus angusfi & & & & $\mathrm{x}$ & & & & \\
\hline Astutumun loutosi & & & & $x$ & $x$ & & $x$ & \\
\hline Astatumen rumuzzoltii & & & & & & & $\mathrm{x}$ & \\
\hline Diphusscon numrusi & & & & $\mathrm{x}$ & & & & \\
\hline Diphussem (Diphascon) alyinum & & & & & & & $x$ & \\
\hline Diphlascon (Diphlescon) brevipus & & & & $\mathrm{x}$ & $x$ & & $\mathrm{x}$ & \\
\hline Diphusson (Diphirsaon) Inullatum & & & & $\mathrm{x}$ & $\mathrm{x}$ & & $x$ & \\
\hline Diphascon (Diphascon) iftamsi & & & & & & & & $x$ \\
\hline Diphusscont (Diphusamen) nobilei & & & & & & & $x$ & \\
\hline Diphlascon (Ixphacscon) pingue & & & $\mathrm{x}$ & $\mathrm{x}$ & $x$ & & $x$ & $x$ \\
\hline Diphasson (Diphlascon) reamicri & & & & $x$ & $x$ & & $\mathrm{x}$ & \\
\hline 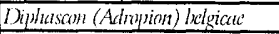 & & & $\mathrm{x}$ & & & & $x$ & \\
\hline Dipluiscon (Adropion) scoticum & & & $x$ & $x$ & $x$ & & $\mathrm{x}$ & \\
\hline Rembezottius anomuiltes & & & & & $\mathrm{x}$ & & & $\mathrm{x}$ \\
\hline Retrumzzottius ollerducteuseri & & $\mathrm{x}$ & $\mathrm{x}$ & $\mathrm{x}$ & $x$ & & $x$ & $x$ \\
\hline Milnesium turdigradum & & $x$ & $x$ & $\bar{x}$ & $x$ & & & $x$ \\
\hline
\end{tabular}


2. táblázat: Somogy megyei vizsgálati mintákban előforduló Tardigrada fajok

\begin{tabular}{|c|c|c|}
\hline & $\begin{array}{l}\text { Avizsgálati ninta } \\
\text { scármzási helve }\end{array}$ & 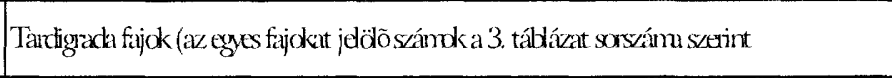 \\
\hline 1. & Balatonföldvár & $6,11,14,17,18,20,23,32,34,38,53,54,55$ \\
\hline 2. & Bulatonlelle & 0 \\
\hline 3. & Balatonmúriafüxdô & $11,20,54,55$ \\
\hline 4. & Balatonszanes & $32,34,36,54,55$ \\
\hline 5. & Barcs & $\begin{array}{l}3,6,8,10,11,13,14,18,20,21,22,23,24,25,27,29,30,32,33,34,39,40,41,43,45 \\
46,48,49,50,51,52,54,55\end{array}$ \\
\hline 6. & Bárdudvaunok & $10,11,14,31,35,46$ \\
\hline 7. & Bedavár & $10,11,12,13,14,16,17,19,20,23,24,26,32,35,38,41,42,45,46,54$ \\
\hline 8. & Bószánfa & $11,14,18,20,23,34,41,45,46$ \\
\hline 9. & Bursák & $11,54,55$ \\
\hline 10. & Cserénfa & 14,55 \\
\hline I1. & Durány & $6,10,11,14,18,20,22,23,24,30,32,34,35,36,41,43,46,49,50,52,54,55$ \\
\hline 12. & Cálosfa & 0 \\
\hline 13. & Hollád & $14,23,30,34,54$ \\
\hline 14. & Igal & 0 \\
\hline 15. & Kadarkát & $1,2,4,7,53$ \\
\hline 16. & Kapdy & $11,14,31,54$ \\
\hline 17. & Kerseliget & $11,14,20,31,39$ \\
\hline 18. & Kéthely & $11,54,55$ \\
\hline 19. & Masdós & 11,32 \\
\hline 20. & Nagypusata & 31 \\
\hline 21. & Nenesvid & $14,32,47,49$ \\
\hline 22. & Siófok & $11,38,54,55$ \\
\hline 23. & Samogysámsan & $5,8,14,54$ \\
\hline 24 & Szenna & $11,14,18,20,21,23,29,34,45,46,49,52$ \\
\hline 25. & Szentbalázs & 31 \\
\hline 26. & Szentbarbús & $14,20,26,32,34,38,46,54$ \\
\hline 27. & Saldk & 14,20 \\
\hline 28. & Tab & 11,14 \\
\hline 29 . & Táska & $11,20,21,22,37,54,55$ \\
\hline 30. & Tótúffalu & $10,11,13,14,17,20,26,41,42,46,48,49,51,52,54$ \\
\hline 31. & Vizvár & $10,11,13,14,20,24,25,32,33,35,41,44,46,54$ \\
\hline 32. & Zala & $6,11,14,54$ \\
\hline 33. & Zákány & 5,18 \\
\hline 34. & Zselidkisfalud & $11,18,20,23,30,34,45,49$ \\
\hline 35. & Zsedidkislak & $6,9,10,11,14,15,20,21,28,32,41,49,50,53,54,55$ \\
\hline
\end{tabular}




\section{3. táblázat: Tardigrada fajok előfordulása Somogy megyében}

\begin{tabular}{|c|c|c|}
\hline & Faj & $\begin{array}{l}\text { Elôfordulási hely (az egyes helységeket jelöló számok a 2. táblázat sorszáma } \\
\text { szerint }\end{array}$ \\
\hline 1. & Echiniscus hisetosus & 15 \\
\hline 2. & Echiniscus canadonsis & 15 \\
\hline 3. & Echiniscus granulatus & 5 \\
\hline 4. & Echiniscus mediantus & 15 \\
\hline 5. & Echiniscus quadrispinosus & 23,33 \\
\hline 6. & Echiniscus testudo & $1,5,11,32,35$ \\
\hline 7. & Echiniscus trisetosus & 15 \\
\hline 8. & $P_{\text {seudechiniscus suillus }}$ & 5,23 \\
\hline 9. & Macrobiotus areolatus & 35 \\
\hline 10. & Macrobiotus harmsworthi & $5,6,7,11,30,31,35$ \\
\hline 11. & Macrobiotus hufelandi & $1,3,5,6,7,8,9,11,16,17,18,19,22,24,28,29,30,31,32,34,35$ \\
\hline 12. & Macrobiotus macrocalix & 7 \\
\hline 13. & Macrobiotus pallarii & $5,7,30,31$ \\
\hline 14. & Macrobiotus richtersi & $1,5,6,7,8,10,11,13,16,17,21,23,24,26,27,28,30,31,32,35$ \\
\hline 15. & Macrobiotus subintermedius & 35 \\
\hline 16. & Xerobiotus pseudohufelandi & 7 \\
\hline 17. & Minibiotus furcatus & $1,7,30$ \\
\hline 18. & Minibiotus intermedius & $1,5,8,11,24,33,34$ \\
\hline 19. & Hexapodibius bindae & 7 \\
\hline 20. & Hypsibius convergens & $1,3,5,7,8,11,17,24,26,27,29,30,31,34,35$ \\
\hline 21. & Hypsibius dujardini & $5,24,29,35$ \\
\hline 22. & Hypsibius microps & $5,11,29$ \\
\hline 23. & Hypsibius pallidus & $1,5,7,8,11,13,24,34$ \\
\hline 24. & Isohypsibius bakonyiensis & $5,7,11,31$ \\
\hline 25. & Isohypsibius brevispinosus & 5,31 \\
\hline 26. & Isohypsibius dastychi & $7,26,30$ \\
\hline 27. & Isohypsibius helenae & 5 \\
\hline 28. & Isohypsibius leithaicus & 35 \\
\hline 29. & Isohypsibius mihelcici & 5,24 \\
\hline 30. & Isohypsibius nodosus & $5,11,13,34$ \\
\hline 31. & Isohypsibius pappi & $6,16,17,20,25$ \\
\hline 32. & Isolypsibius prosostomus & $1,4,5,7,11,19,21,26,31,35$ \\
\hline 33. & Isohypsibius ronsisvallei & 5,31 \\
\hline 34. & Isohypsibius schaudinni & $1,4,5,8,11,13,24,26,34$ \\
\hline 35. & Isohypsibius silvicola & $6,7,11,31$ \\
\hline 36. & Isohypsibius tetradactyloides & 4,11 \\
\hline 37. & Isohypsibius undulatus & 29 \\
\hline 38. & Eremobiotus alicatai & $1,7,22,26$ \\
\hline 39. & Dorpphoribius macrodon & 5,17 \\
\hline 40 . & Pseudobiotus augusti & 5 \\
\hline 41. & Astatumen bartosi & $5,7,8,11,30,31,35$ \\
\hline 42. & Astatumen ramazzottii & 7,30 \\
\hline 43. & Diphascon marcusi & 5,11 \\
\hline 44. & Diphascon (Diphascon) alpinum & 31 \\
\hline 45. & Diphascon (Diphascon) brevipes & $5,7,8,24,34$ \\
\hline 46. & Diphascon (Diphascon) bullatum & $5,6,7,8,11,24,26,30,31$ \\
\hline 47. & Diphascon (Diphascon) iharosi & 21 \\
\hline 48. & Diphascon (Diphascon) nobilei & 5,30 \\
\hline 49. & Diphascon (Diphascon) pingue & $5,11,21,24,30,34,35$ \\
\hline 50. & Diphascon (Diphascon) recamieri & $5,11,35$ \\
\hline 51. & Diphascon (Adropion) belgicae & 5,30 \\
\hline 52. & Diphascon (Adropion) scoticum & $5,11,24,30$ \\
\hline 53. & Ramazzottius anomalus & $1,15,35$ \\
\hline 54. & Ramazzottius oberhaeuseri & $1,3,4,5,7,9,11,13,16,18,22,23,26,29,30,31,32,35$ \\
\hline 55. & Milnesium tardigradum & $1,3,4,5,9,10,11,18,22,29,35$ \\
\hline
\end{tabular}




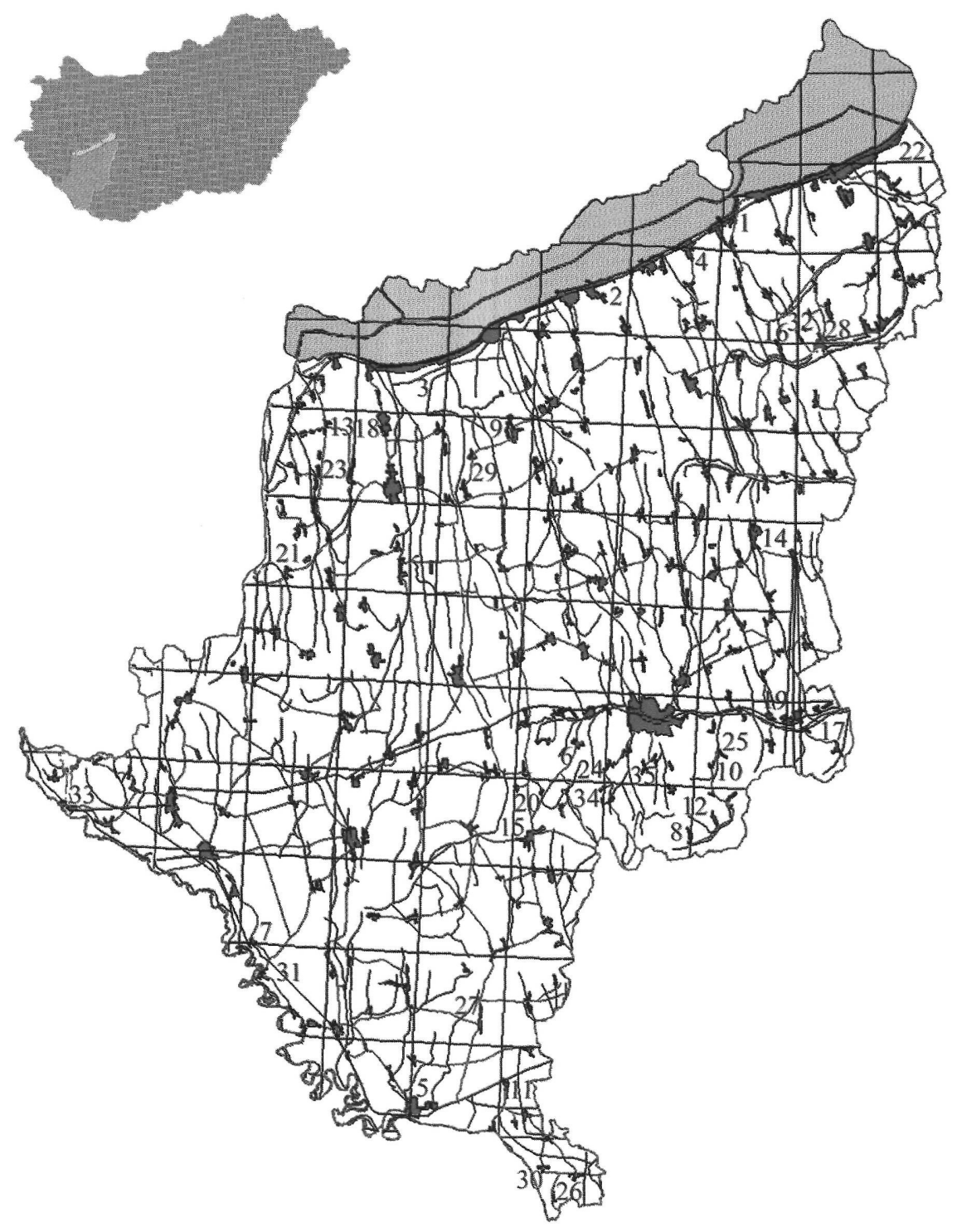

1. ábra: Tardigrada vizsgálatok mintavételi helyei

(A mintavételi helyek sorszámozása a 2. táblázat adatai szerint történt) 1.Balatonboglár, 2.Balatonlelle, 3.Balatonmáriafürdő, 4.Balatonszemes, 5.Barcs, 6.Bárdudvarnok, 7.Bélavár, 8.Böszénfa, 9.Buzsák, 10 Cserénfa, 11.Darány, 12.Gálosfa, 13.Hollád, 14.Igal, 15.Kadarkút, 16.Kapoly, 17.Kercseliget, 18. Kéthely, 19.Mosdós, 20.Nagypuszta, 21.Nemesvid, 22.Siófok, 23.Somogysámson, 24.Szenna, 25.Szentbalázs, 26.Szentborbás, 27.Szulok, 28.Tab, 29.Táska, 30.Tótújfalu, 31.Vízvár, 32.Zala, 33.Zákány 34.Zselickisfalud, 35.Zselickislak 
4. táblázat: A Somogy megye területéról kimutatott Tardigrada fajok és rendszertani egységek száma

Törzs Osztály Rend Család $\quad$ Nem Fajszám

Tardigrada Heterotardigrada Echiniscoidea Echiniscidae Echiniscus 7

$\begin{array}{cc}\text { (8 faj) } & \text { (8 faj) } \\ \text { Eutardigrada } & \text { Parachela } \\ \text { (47 faj) } & \text { (46 faj) }\end{array}$

(8 faj)
Macrobiotidae
(10 faj)

Pseudechiniscus $\quad 1$

Macrobiotus 7

(47 faj)

Összesen

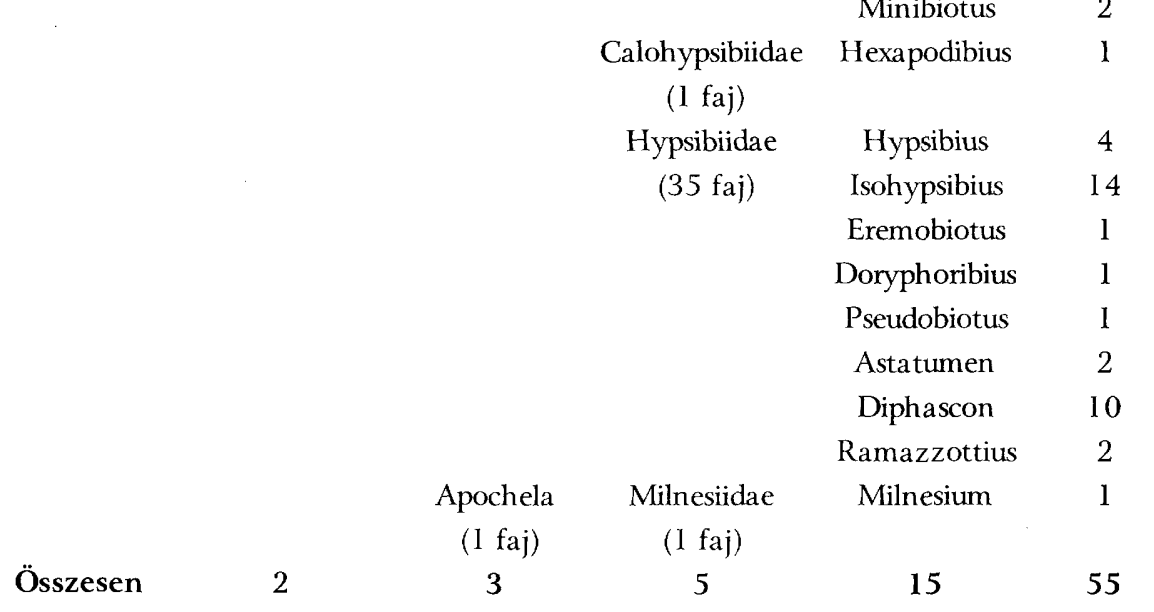

Xerobiotus 1

Minibiotus 2

Hexapodibius 1

\section{5. táblázat: A Somogy megye területéról leírt Tardigrada fajok listája}

Heterotardigrada Marcus, 1927

Echiniscoidea Marcus, 1927

Echiniscidae Thulin, 1928

Echiniscus Schultze, 1840

Echiniscus bisetosus Heinis, 1908

Echiniscus canadensis Murray, 1910

Echiniscus granulatus (Doyére, 1840)

Echiniscus mediantus Marcus, 1930

Echiniscus quadrispinosus Richters, 1902

Echiniscus testudo (Doyére, 1840)

Echiniscus trisetosus Cuénot, 1932

Pseudechiniscus Thulin, 1928

Pseudechiniscus suillus (Ehrenberg, 1853)

Eutardigrada Marcus, 1927

Parachela Schuster, Nelson, Grigarick et Christenberry, 1980

Macrobiotidae Thulin, 1928

Macrobiotus Schultze, 1834

Macrobiotus areolatus Murray, 1907

Macrobiotus harmsworthi Murray, 1907

Macrobiotus hufelandi Schuitze, 1833

Macrobiotus macrocalix Bertolani et Rebecchi, 1993

Macrobiotus pallarii Maucci, 1954

Macrobiotus richtersi Murray, 1911

Macrobiotus subintermedius Ramazzotti, 1962

Xerobiotus Bertolani et Biserov, 1996

Xerobiotus pseudohufelandi (Iharos, 1966)

Minibiotus Schuster, Nelson, Grigarick et Christenberry, 1980

Minibiotus furcatus (Ehrenberg, 1859) 


\title{
5. táblázat folytatása: A Somogy megye területéról leírt Tardigrada fajok listája
}

\author{
Minibiotus intermedius (Plate, 1888) \\ Calohypsibiidae Pilato, 1969 \\ Hexapodibius Pilato, 1969 emended Maucci, 1981 \\ Hexapodibius bindae Pilato, 1982 \\ Hypsibiidae Pilato, 1969 \\ Hypsibius Thulin, 1928 \\ Hypsibius convergens (Urbanowicz, 1925) \\ Hypsibius dujardini (Doyére, 1840) \\ Hypsibius microps Thulin, 1928 \\ Hypsibius pallidus Thulin, 1911 \\ Isohypsibius Thulin, 1928 \\ Isohypsibius bakonyiensis (Tharos, 1964) \\ Isohypsibius brevispinosus (Iharos, 1966) \\ Isohypsibius dastychi Pilato, Bertolani et Binda, 1982 \\ Isohypsibius helenae (Iharos, 1964) \\ Isohypsibius leithaicus (Iharos, 1966) \\ Isohypsibius mihelcici (Iharos, 1964) \\ Isohypsibius nodosus (Murray, 1907) \\ Isohypsibius pappi (Iharos, 1966) \\ Isohypsibius prosostomus Thulin, 1928 \\ Isohypsibius ronsisvallei (Binda et Pilato, 1969) \\ Isohypsibius schaudinni (Richters, 1909) \\ Isohypsibius silvicola (Iharos, 1966) \\ Isohypsibius tetradactyloides (Richters, 1907) \\ Isohypsibius undulatus Thulin, 1928 \\ Eremobiotus Biserov, 1992 \\ Eremobiotus alicatai (Binda, 1969) \\ Doryphoribius Pilato, 1969 \\ Doryphoribius macrodon Binda, Pilato et Dastych, 1980 \\ Pseudobiotus Schuster, Nelson, Grigarick et Christenberry, 1980 \\ Pseudobiotus augusti (Murray, 1907) \\ Astatumen Pilato, 1997 \\ Astatumen bartosi (Weglarska, 1959) \\ Astatumen ramazzottii (Iharos, 1966) \\ Diphascon Plate, 1889 \\ Diphascon marcusi (Rudescu, 1964) \\ (Diphascon Pilato, 1987) \\ Diphascon (Diphascon) alpinum Murray, 1906 \\ Diphascon (Diphascon) brevipes (Marcus, 1936) \\ Diphascon (Diphascon) bullatum Murray, 1905 \\ Diphascon (Diphascon) iharosi Vargha, 1995 \\ Diphascon (Diphascon) nobilei (Binda, 1969) \\ Diphascon (Diphascon) pingue (Marcus, 1936) \\ Diphascon (Diphascon) recamieri Richters, 1911 \\ (Adropion Pilato, 1987) \\ Diphascon (Adropion) belgicae Richters, 1911 \\ Diphascon (Adropion) scoticum Murray, 1905 \\ Ramazzottius Binda et Pilato, 1986 \\ Ramazzottius anomalus (Ramazzotti, 1962) \\ Apochela Schuster, Nelson, Grigarick et Christenberry, 1980 \\ Ramazzottius oberhaeuseri (Doyére, 1840) \\ Milnesiidae Ramazzotti, 1962 \\ Milnesium Doyére, 1840 \\ Milnesium tardigradum Doyére, 1840
}




\title{
Irodalom
}

IHAROS, GY., 1937: A magyarországi medveállatocskák - Math. és Term. tud. Ért. 56: 982 - 1040. IHAROS, GY., 1960: Neuere Beiträge zur Kenntnis der Tardigraden - Fauna Ungarns. III. -Opusc. zool. 3: 137 - 144 .

IHAROS, GY., 1981 : Elôzetes adatok a Barcsi borókás tájvédelmi körzet Tardigrada - faunájáról Dunántúli Dolg. Term. tud. Sor. 2: 43 - 44.

IHAROS, GY., 1985: A Barcsi borókás Tardigrada faunája - Dunántúli Dolg. Term. tud. Sor. 5: 71 - 84. IHAROS, GY ., VARGHA, B., 1995 : Tardigradák a Zselic területéról - Janus Pannonius Múz. Évk. 39 : 33 - 38.

VARGHA, B., 1996: New data to the Hungarian tardigrade fauna with a revised list of species - Fol. ent. hung. 57: $285-290$.

VARGHA, B., 1998: Adatok a Duna - Dráva Nemzeti Park medveállatka (Tardigrada) faunájához Dunántúli Dolg. Term. tud. Sor. 9:73 - 80 .

\section{Occurence of the water - bear (Tardigrada) species in Somogy county}

\section{VARGHA BÉla - IHAROS GYULA}

From the tardigrade species of Somogy county, (IHAROS 1937, 1960, 1981, 1985, IHAROS and VARGHA 1995 and VARGHA 1996, 1998 and recent study) (Table 1.) are reported. Tables 2 . and 3 . show the tardigrade species in various sampling sites and the species occurence, table 4 . contains the number of tardigrade species and various systematical units and Table 5. shows the list of the tardigrade species concerning Somogy county.

At present 55 species are known from the area of Somogy county representing $45 \%$ of the Hungarian tardigrade fauna and $48 \%$ of the Transdanubian region's tardigrade fauna.

\author{
Authors' address: \\ Dr. Béla VARGHA \\ National Institute of Environmental Health \\ H-1097 Budapest \\ Gyáli út $2-6$. \\ HUNGARY \\ Dr. Gyula IHARos \\ H-8646 Balatonfenyves \\ Templom köz 7 . \\ HUNGARY
}

